\title{
Burning Mouth Syndrome: Update
}

\author{
Juliana Cassol Spanemberg ${ }^{1}$, Eugenia Rodríguez de Rivera Campillo², Enric Jané Salas², José López \\ López $^{3}$
}

${ }^{1} \mathrm{PhD}$ Student, Stomatology and Bucomaxilofacial Cancer Prevention Division, São Lucas Hospital, Pontifical Catholical University of Rio Grande do Sul (PUCRS), Porto Alegre, Brazil. '2Professor of Oral Pathology, School of Dentistry, University of Barcelona, Spain. ${ }^{3}$ Department of Odontoestomatology - School of Dentistry, Pabellón de Gobierno, C/Feixa LLarga s/n 08907 L'Hospitalet de Llobregat. Barcelona, Spain.

\begin{abstract}
Burning Mouth Syndrome (BMS) is a chronic disorder that predominately affects middle-aged women in the postmenopausal period. The condition is distinguished by burning symptoms of the oral mucosa and the absence of any clinical signs. The etiology of BMS is complex and it includes a variety of factors. Local, systemic and psychological factors such as stress, anxiety and depression are listed among the possible causes of BMS. BMS may sometimes be classified as BMS Type I, II or III. Although this syndrome is not accompanied by evident organic alterations and it does not present health risks, it can significantly reduce the patient's quality of life. This study analyzes the available literature related to BMS, and makes special reference to its therapeutic management. The pages that follow will also discuss the diagnostic criteria that should be respected, etiological factors, and clinical aspects. We used the PubMed database and searched it by using the keywords "burning mouth syndrome", "BMS and review", and "burning mouth and review", in the title or abstract of the publication. BMS treatment usually steers towards the management of the symptoms; however, the specific local factors that could play a significant role in worsening the oral burning sensation should be eradicated. The most widely accepted treatment options that show variable results include tricyclic antidepressants, benzodiazepines and antipsychotic drugs; nevertheless there are other therapies that can also be carried out. Professionals that work in the field of dentistry should formulate standardized symptomatic and diagnostic criteria in order to more easily identify the most effective and reliable strategies in BMS treatment through multidisciplinary research.
\end{abstract}

Key Words: Burning mouth syndrome, Etiology, Diagnosis, Treatment

\section{Introduction}

Burning Mouth Syndrome (BMS) is distinguished by burning, pain, or symptoms of itching in oral mucosa, which arise without the presence of any changes in physical examinations, laboratory analysis, or salivary flow rates [1-5]. This condition tends to appear in middle-aged and elderly women [6-9]. The International Association for the Study of Pain defines BMS as a pain that lasts for at least 4-6 months of duration and which is located on tongue or in other mucosal membranes and that is presented in the absence of any clinical and/or laboratory findings. The terms "glossodynia" (painful tongue) and "glossopyrosis" (burning tongue), as well as "glossalgia", describe the phenomenon present in this disorder with respect to the most affected area, the tongue (especially the tip and lateral borders). Other terms such as "stomatodynia", "stomatopyrosis", "oral dysesthesia", and "burning mouth syndrome" are used to define this condition [10]. Although percentages in research findings may vary between $.07 \%$ and $15 \%$, we can state that this disease is highly prevalent [11].

The episodes of a burning sensation are described as being spontaneous and the symptoms that patients experience range in severity; some patients suffer from a moderate burn, while others experience intolerable pain $[3,12]$. Other changes in sensitivity are known to take place, besides oral stinging, which include: a feeling of dryness in the mouth [13-15] or gustative alterations, such as the perception of a bitter or metallic taste [16]. In certain instances dysesthesia in the mouth might also occur, which is characterized by the feeling of having sand in the mouth or swelling of the mouth $[12,16,17]$.
The lack of unified criteria makes the diagnosis even more complicated, and consequently, epidemiological information can differ depending on the researcher who analyzes it $[18,19]$. Within the risk group of postmenopausal-women, the prevalence of this disorder ranges between $18 \%$ and $33 \%$ [20]. The majority of research conducted shows an evident predominance that women have over men, ranging between 3-1 and 9-1 for the female sex [21-24]. According to most of the authors, the typical average age of patients of BMS is from 50 to 60 years old, however, it can also arise in patients close to their thirties, but not in children or in teenagers.

The true cause BMS remains unknown. Although this syndrome is not accompanied by evident organic alterations and it does not present health risks, it can significantly reduce the patient's quality of life. BMS patients tend to have a history of frequent medical and dental visits with the objective of obtaining a cure that does not yet exist. Experts currently debate whether the psychological alterations that BMS patients experience are the cause or the consequence of such chronic pain [25-27]. The patient profile is rather specific and is comprised of the following personal characteristics: age range between 50 and 60 , a history of prolonged suffering from chronic pain, and a history of having been treated by many different specialists without obtaining any solution to the problem. It is also often accompanied by a significant emotional profile and is usually related to cancerophobia [28].

Diligent clinical investigation fails to accurately identify the cause for the burning sensation in patients with true burning mouth syndrome. Specific criteria should be observed, since

Corresponding author: José López López, Bellvitge University Campus, Department of Odontoestomatology - School of Dentistry, Pabellón de Gobierno, C/Feixa LLarga s/n 08907 L'Hospitalet de Llobregat. Barcelona, Spain, Tel: +34-606457362; e-mail: 18575j11@gmail.com 
symptoms of oral burning are common and can be caused by either local or systemic factors, which do not describe true BMS [15-17,28]. The clinical or laboratorial conditions associated with burning mouth include candidiasis, geographic tongue, hyposalivation, esophagic reflux, parafunctional habits, diabetes, nutritional deficiencies (iron, folate, $\mathrm{B}_{1}, \mathrm{~B}_{2}$, $\mathrm{B}_{6}, \mathrm{~B}_{12}$ ), and adverse effects of certain drugs. In such cases, if the cause of this disorder is eliminated, the patient will therefore experience symptom relief [29].

This study analyzes the available literature related to BMS, and makes special reference to its therapeutic management. Other important topics of discussion throughout this article also include the diagnostic criteria that should be followed, etiological factors, and clinical aspects of the disease.

A search in the PubMed database was performed in order to identify articles published in the last five years using the key words: "burning mouth syndrome", "BMS and review", and "burning mouth and review". This search resulted in 259 articles. When we limited the search to articles published in the English language, we found 6 non-systematic reviews and one systematic review that we considered particularly relevant (Table 1)".

The objective of this article was to perform a literature review on BMS based on three main sections: pathogenesis, diagnosis, and treatment, with a special focus on the latter.

\section{Pathogenesis}

The origin of BMS includes a variety of factors. We can divide the possible causes of BMS into local factors [26,30$36]$, systemic factors [26,37] and psychological factors such as: stress, anxiety and depression $[2,12,30,31,37,38]$. At times BMS can be directly related to a pathogenic factor that can act in either a local or systemic way. However, there are certain cases of idiopathic stomatodynia in which none of them are shown [39].

According to some authors, BMS is included within the group of diseases categorized by idiopathic orofacial pain [40]. Such disease share the common features that in all cases the pain is continuous, it is chronic for several months, and then it disappears while the patient is sleeping. It is known to be more common in women and it is closely related to psychosocial disorders [11,30].

Local allergic reactions may also have a possible influence on the etiology of BMS. Possible allergens include: allergens from dental materials or materials used in the manufacturing of prosthesis, especially in type III patients [41]. However, throughout the BMS literature there are some authors who do not pay special attention to such factors [42]. There are other agents and/or elements that must also be taken into account, these include: cosmetics, toothpastes and mouthwashes, all of which could provoke the sensation of oral burning and stinging [39].

Table 1. Most significant conclusions from the articles.

\begin{tabular}{|c|c|c|}
\hline Article & Aspects from the review & Most relevant conclusions \\
\hline Abetz and Savage [32] & $\begin{array}{l}\text { No systematic review. } \\
\text { This publication serves as a review of BMS } \\
\text { clinical presentation and focuses on contributing } \\
\text { factors in the initial presentation of the } \\
\text { condition, as well as its advancement. }\end{array}$ & $\begin{array}{l}\text { A number of useful clinical indicators were proposed in this } \\
\text { paper, these indicators or signs may prove to be helpful for } \\
\text { both clinical assessment and subsequent patient discussions, } \\
\text { seeing as they provide visible supportive evidence for the } \\
\text { diagnosis. The main focal point of the article was the role of } \\
\text { psychological disorders in the etiology of BMS, in addition } \\
\text { to a presentation that highlighted the clinical management of } \\
\text { patients. }\end{array}$ \\
\hline Balasubramaniam et al. [16] & $\begin{array}{l}\text { No systematic review. } \\
\text { The article reviews different conditions and } \\
\text { diseases that may be possible causes of oral } \\
\text { burning. }\end{array}$ & $\begin{array}{l}\text { The article provided knowledge about the local, systemic and } \\
\text { psychosocial factors that can cause the onset of oral burning, } \\
\text { which is associated with secondary BMS. }\end{array}$ \\
\hline López-Jornet et al. [9] & $\begin{array}{l}\text { No systematic review. } \\
\text { The article reviews some recent studies related } \\
\text { to BMS literature, especially those having } \\
\text { to do with etiological factors that could be } \\
\text { involved, clinical aspects, diagnostic criteria and } \\
\text { therapeutic management. }\end{array}$ & $\begin{array}{l}\text { The article included tables that helped to guide us through } \\
\text { the clinical factors, diagnosis and treatment of burning } \\
\text { mouth syndrome. It made the suggestion of the inclusion and } \\
\text { exclusion protocols based on suggestions made throughout } \\
\text { other literary sources. }\end{array}$ \\
\hline Minguez-Sanz et al. [29] & $\begin{array}{l}\text { No systematic review. } \\
\text { The article describes different hypotheses } \\
\text { relating to BMS etiology, as well as the } \\
\text { psychological and anatomical data that serve as } \\
\text { the basis for such hypotheses. }\end{array}$ & $\begin{array}{l}\text { The study went in depth to describe the different theories that } \\
\text { have been proposed as an explanation for the primary and } \\
\text { idiopathic BMS etiology. }\end{array}$ \\
\hline De Moraes et al. [34] & $\begin{array}{l}\text { Systematic review. } \\
\text { This study reviews several randomized clinical } \\
\text { trials related to BMS treatment strategies. }\end{array}$ & $\begin{array}{l}\text { The paper provided evidence in favor of the effectiveness } \\
\text { of therapies and their main side effects with the objective of } \\
\text { contributing to better therapeutic management of BMS. }\end{array}$ \\
\hline Jääskeläinen [28] & $\begin{array}{l}\text { No systematic review. } \\
\text { This review recaps the recent neurophysiologic, } \\
\text { psychophysical, neuropathological, and brain } \\
\text { imaging evidence for neuropathic mechanisms } \\
\text { in primary BMS. }\end{array}$ & $\begin{array}{l}\text { The study set forth a thorough neurophysiological, } \\
\text { psychophysical and neuropathological BMS approach. }\end{array}$ \\
\hline Spanemberg et al. [35] & $\begin{array}{l}\text { No systematic review. } \\
\text { Different options for the management of BMS } \\
\text { patients are proposed. These include etiological } \\
\text { and therapeutical ones. }\end{array}$ & $\begin{array}{l}\text { The article focused on BMS etiological and treatment options. } \\
\text { In addition to this, it included a table summarizing the BMS } \\
\text { placebo treatment. }\end{array}$ \\
\hline
\end{tabular}


Some authors consider xerostomia to be one of the most important coexisting causes and they directly relate it to the onset of BMS [43,44].

Systemic factors such as vitamin deficiencies, that can produce significant alterations on the tongue, may also play an important role in the development of burning mouth. Different types of glossitis can appear depending on the deficiencies of riboflavin, nicotinic acid, and ascorbic acid, and as a result of the alteration in sensitive receptors and, in some degree, to the atrophy of the oral epithelium. Due to all of these factors, the mucosal sensitivity to external agents is increased $[45,46]$. Diabetes mellitus is frequently accompanied by stomatodynia, which can be produced by two mechanisms: peripheral neuropathy of the sensory nerves of oral mucosa and/or by the degree of xerostomia associated with fungal infection [47].

Although no study has yet demonstrated their direct relationship with burning mouth syndrome [48], it is true that psychological factors play an important role in the onset of BMS [48]. According to some authors, stress is not considered to be a crucial factor in the appearance of BMS symptomatology [48], however the majority of these authors do agree that there is a significant relationship between the existence of psychogenic alterations (such as: anxiety, cancerphobia, and depression) and the manifestation of BMS.

Femiano et al. [2] have shown that patients who suffer from BMS exhibit a decrease in self-esteem, the absence of a solid and satisfactory personality, and they experience significant losses and important changes in their lives before being affected by the syndrome. Patients with BMS, as mentioned by Gao et al. [11], have suffered many unfavorable or negative events throughout their lives, when comparing them to the control-patients. Palacios-Sánchez [49] believes that there is an obvious link between the affective life alteration and the syndrome's onset. Patients who suffer from BMS have proved to have significantly higher levels of anxiety in their lives, as well as higher salivary cortisol levels than those of the control-patients [50].

Disorders of the hormone balance may be related to BMS in women as the disease is more frequent during and after menopause [23,37,51]. Tarkkila et al. [23] evaluated the relation between oral discomfort and menopause in 3173 patients, verifying that $8 \%$ of these women exhibited burning sensations of the oral tissues. However, hormone replacement therapy did not prevent the occurrence of symptoms. In Forabosco et al. [37] symptoms of BMS were found in $46 \%$ of women at menopause and approximately $60 \%$ showed relief after hormone replacement. The authors attributed the relief of oral discomfort following hormone therapy, to the presence of oestrogen receptors on the oral mucosa.

\section{Clinical Signs and Diagnosis}

The clinical manifestation of BMS is described by a continual hot, burning and painful sensation that lasts throughout the day. It is a chronic disease that appears at different locations within the oral cavity, all of course in the absence of any type of lesion that could justify the symptoms, as well as any clinical or histological changes [39,52]. Patients tend to complain of a sensation of dry mouth and palate alterations, which include a metallic or bitter taste [24,35].
The tongue is the most common location of BMS manifestation (at the tip and at the lateral edges), together with lips, especially the lower lip [39]. The description of the symptomatology varies depending from patient to patient, although the majority of them describe the symptoms as unbearable and with prolonged evolution. The feeling of discomfort tends to be continuous, or it can be intermittent, and it often worsens throughout the day. Some patients, however, experience days without any symptoms.

It is important for us to consider that the burning sensation can worsen in the presence of specific foods, such as spicy food or acidic fruit, and it can even improve with intake of liquids, salivary stimulants or with certain foods. Many patients notice an improvement when they consume sweets or chewing gum, since their mouth is normally dry and left with a bad taste, due to the fact that they are taking xerostomia causing drugs (antidepressants, anxiolytics or hypotensive drugs, among others). Additionally, very hot or very cold food can aggravate or improve the BMS related discomfort [39].

BMS is usually sometimes divided into three different types [53]. Both types I and II involve continual daily discomfort. For type III patients, those that experience asymptomatic periods, the main precipitating factor is emotional instability, although the onset of symptoms is also related to the exposure to a possible allergenic factor that triggers a contact allergy $[54,55]$. This classification can be useful in intuiting the prognosis and, at the same time, it allows us to guide the patients towards the need involve different specialists such as allergologist, psychiatrists and/or psychologists; although patient classification based on those three groups is not always an easy task.

The symptoms affect the patients' quality of life $[9,31,52,56,57]$ and due to the significant emotional component that goes along with BMS, it is advisable that these patients' visits be quiet, one-on-one with the physician, and held in a relaxed environment so that he/she can explain his/her familiar and affective situation. These patients need time and dedication from their medical professional, seeing as they want to be heard and understood. Patient reassurance is paramount $[31,57]$. BMS patients tend to be characterized by a common profile; this profile is later summarized in Table 2.

The sensation of xerostomia or dry mouth is something that the majority of BMS patients experience although, in most of them, it is not possible to demonstrate a significant reduction in salivary flow [39]. More often than not, patients report symptoms of thick and filamentous saliva. There are few unusual cases in which the oral dryness has made food intake difficult. On the other hand, the majority of BMS patients report improvements with respect to their overall discomfort and the burning sensation during food intake.

BMS diagnosis is fundamentally based on clinical signs. It is necessary to correctly examine the patient, discarding the existence of systemic and local factors that could cause such symptoms $[39,52,55,57,58]$. The administration of a blood test is also highly recommended. In the case that any deficit should appear, replacement therapy will be initiated, and if in spite of this therapy the symptomatology persists, we at that point face idiopathic BMS, and therefore, we must begin with symptomatic treatment. 
Table 2. Profile of patients with burning mouth syndrome.

Most common in middle-aged or elderly women

Characterized by a burning, stinging and/or itching sensation

Patients usually experience a metallic or bitter taste

Oral discomfort is usually chronic and it lasts over time (months or years)

Patients usually experience dry mouth or a sensation of thick saliva No clinical lesions related to the area of discomfort

Symptoms don't interfere with patients' ability to sleep, although most of them have trouble sleeping or take drugs in order to be able to sleep better

Oral discomfort can be continuous or intermittent and it tends to worsen throughout the day

Symptoms don't worsen while eating or drinking, they can even improve

Patients usually have a history of having visited different specialists and having taken numerous drugs without observing any improvement

They usually have a significant anxious or depressive factor, sometimes accompanied by cancerophobia

Clinical manifestations are usually triggered by psychological stress and they often appear after a dental treatment or a surgical intervention

Sometimes there is a clear beginning is marked, but with no clear trigger

Thanks to internet and social networking websites, many patients can self-diagnose

\section{Treatment}

BMS treatment is currently still posing serious problems, since the etiopathogenic factors that produce the onset of the disease, make it difficult to achieve advances in treatment. The main objective of the treatment is to control the various factors that are related to BMS, therefore decreasing the symptoms that are described by the patients.

As mentioned in some studies, topical capsaicin (Capsicum frutescens $L$ ) can be used to control neuropathic pain, since this drug has an effect on the sensory afferent neurons and also serves as an analgesic $[51,59,60]$. However, the use of capsaicin has been reduced since it has been proven to evoke an even worse burning sensation at the beginning of the treatment period [59]. It is important to note that there have not been any cases in which this BMS treatment drug has been investigated in placebo-controlled studies.

Medicine such as tricyclic antidepressants, benzodiazepines, and antipsychotic drugs have been researched and are considered to be the three most widely accepted options for the treatment of BMS, despite the fact that they produce hyposalivation and xerostomia. Treatment methods like psychotherapy and psychoactive drugs were prescribed for BMS patients once it was demonstrated that psychological factors play an important role in this disorder [61]. Bergdahl et al. [61] treated BMS patients by means of cognitive behavior therapy once a week for between 12 and 15 weeks. They were able to observe a decrease in the intensity of the pain immediately after undergoing the therapy and at the six-month follow-up visit.

The use of topical clonazepam proved to be another treatment option for patients suffering from BMS [51,62-64]. Clonazepam is a benzodiazepine that acts as a GABA receptor agonist. Its main property includes the light inhibition of functions of the central nervous system, thus permitting anticonvulsant action, light sedation, muscular relaxation and a calming effect. Gremeau-Richard et al. [62] propose that the action of topical clonazepam has to do with the dysfunctions of the peripheral nervous system that are observed in patients with the syndrome, and the presence of GABA receptors in peripheral tissues. Another study was carried out in which 33 patients were treated with clonazepam tablets, while the other 33 patients were administered a placebo. The symptoms were then assessed after 1 month and 6 months of the treatment period had elapsed. After only 1 month of treatment, 23 of the 33 patients that were treated with clonazepam reported at least a 50\% reduction in their symptoms [63]. This drug does not show the adverse effects of its systemic use when it is used topically.

In an uncontrolled study paroxetine, a tricyclic antidepressant, was administered to BMS patients throughout a period of 12 weeks [65]. Of these patients, approximately $80 \%$ reported a decrease in their symptoms, with little adverse effects, thus suggesting that paroxetine could be a plausible treatment option for this disorder. Ueda [66] used the antipsychotic drug olanzapine and were therefore able to achieve symptom reduction in two patients that suffered from the syndrome. Olanzapine is classified as a potent antagonist of dopamine, norepinephrine and serotonin neuron receptors. However, in order to confirm the effectiveness of this drug, and to explain its mechanisms of action, the realization of controlled studies is needed.

A drug that did not show suitable results in the relief of the symptoms of oral burning was trazodone, a drug that is typically used to treat depression. Trazodone is classified as an atypical antidepressant since it stimulates the presynaptic inhibition of serotonin recaptation, blockage of 5-HT2A and 5HT2C serotonin receptors on post-synapse neurons [58].

Hormonal treatments, or those that involve corticosteroids, phytotherapy, vitamins and trace elements, antifungal drugs and sialogogue drugs have also been described throughout the literature as an attempt to reduce the symptoms reported by the patients, although the studies are not always controlled and the patients' clinical symptoms do not always improve.

Because of alpha-lipoic acid's neuroprotective properties, it has been researched with respect to BMS treatment; however, studies involving this drug have presented controversial results. According to Femiano et al. [2], both patients treated with psychotherapy and those who received $200 \mathrm{mg}$ of ALA three times a day throughout a period of two months, demonstrated significant improvement with respect to their symptoms of BMS. The group that was simultaneously treated with ALA and psychotherapy was the group that showed the most remarkable results. According to the researchers, it is necessary to combine psychotherapy with the drugs, the reason for this being that psychogenic alterations are known to have a strong relation to BMS [2]. Carbone et al. [67], López-Jornet et al. [68] and Cavalcanti and Silveira [29] were not able to demonstrate any significant improvement in BMS patients when utilizing alpha-lipoic acid. Both the placebo effect and the different parameters that were used to calculate the intensity of the symptoms could be the source of possible explanations that account for such conflicting results. 
In a controlled study that consisted of 60 patients, the phytotherapeutic drug Catuama ${ }^{\circledR}$, which is composed of an association of four medicinal herbs, proved to be effective in reducing BMS symptoms in those who suffer from this disorder. The experimental group showed clinical improvement in week 4 and week 8 that was significant when compared to that of the placebo group. After 12 weeks of monitoring, the patients experienced a $51.3 \%$ reduction in their symptoms, whereas the reduction of symptoms in the control group was only about $18.8 \%$ [69]. There were no cases of toxicity with respect to the use of this medicine. In a previous study, Oliveira et al. [70] researched the chronic administration of Catuama ${ }^{\circledR} 25 \mathrm{ml}$, twice a day for 28 days in healthy humans volunteers of both sexes. There were no adverse reactions or relevant hematological and biochemical changes that were presented in the study.

Low power laser radiation therapy has proven to be useful in the reduction of BMS symptoms [71-74]. On the contrary, Vukoja et al. [74] were not able to confirm those results and therefore suggest that the therapeutic benefit of the laser BMS patients was caused by placebo effect. Santos et al. [72] had 10 BMS patients undergo to a low power laser session (lowlevel laser therapy - LLLT) once a week over a 10-week span, utilizing the InGaAIP laser diode in continuous mode. A $660 \mathrm{~nm}$ wavelength, $40 \mathrm{nW}, 20 \mathrm{~J} / \mathrm{cm}^{2}$ of dosimetry and a $0.8 \mathrm{~J}$ per point in 10 seconds was used. Throughout all of the sessions the intensity of the symptoms was evaluated by using a visual analog scale. Patients reported an improvement after laser treatment, with a reduction of symptoms of up to $58 \%$ by the tenth session. On the other hand Kato et al. [71] used the LLLT in 11 patients with BMS at the specific areas where the patients were experiencing symptoms. The affected areas were irradiated once a week, in a continuous mode, with a 790 wavelength and a dosimetry of $6 \mathrm{~J} / \mathrm{cm}^{2}$. The intensity of the symptoms was verified through a VAS at each of the three sessions, as well as six weeks after the treatment was finished. At the end of the study the authors checked that the experimental group did in fact show a significant improvement in their symptoms as compared to their state at the beginning of the treatment. The patients reported a decrease in the intensity of their symptoms after the laser radiation treatment. This decrease was approximately $80.4 \%$, therefore suggesting that LLLT can be an alternative for BMS.

\section{References}

1. Danhauer SC, Miller CS, Rhodus NL, Carlson CR. Impact of criteria-based diagnosis of burning mouth syndrome on treatment outcome. Journal of Orofacial Pain. 2002; 16: 305-311.

2. Femiano F, Gombos F, Scully C. Burning Mouth Syndrome: open trial of psychotherapy alone, medication with alpha-lipoic acid (thioctic acid), and combination therapy. Medicina oral. 2004; 9: 8-13.

3. Cherubini K, Maidana JD, Weigert KL, Figueiredo MA. Síndrome da ardência bucal: revisão de cem casos. Revista Odonto Ciência. 2005; 20: 109-113.

4. Brailo V, Vuéiaeeviae-Boras V, Alajbeg IZ, Alajbeg I, Lukenda $\mathrm{J}$, et al. Oral burning symptoms and burning mouth syndrome-significance of different variables in 150 patients. Medicina oral Patología Oral y Cirugía bucal. 2006; 11: E252-E255.

5. Salort-Llorca C, Mínguez-Serra MP, Silvestre FJ. Drug-
Low power laser therapy is a non-invasive treatment; it is well tolerated by patients and it is useful in treating sharp and chronic pain [40]. Different studies have investigated the possible adverse effects of laser but they were not significant [75,76].

BMS treatment is usually directed towards symptoms management, but local factors they may play a role in worsening the oral burning sensation should be eliminated [77]. These include: alcohol, spicy foods and acidic drinks due to their irritant effect on the oral mucosa. It is necessary to research if BMS symptoms are caused by parafunctional habits, galvanic currents, mechanical irritation, or a denture allergy [6]. With treatment or ridding of such factors, it has been demonstrated that the clinical symptoms improve [37,7779]. This disease has a chronic clinical evolution seeing as patients experience alternating periods of exacerbation of the symptomatology, as well as periods of improvement. In some cases, those who suffer from BMS have also described spontaneous remission [77].

The typical BMS patient seeks diagnosis before undergoing any kind of special treatment. Therefore, the medical professional has the obligation of explaining the nature of BMS and what that implies for the patient. Unfortunately, those who are affected by this disorder must accept that fact and learn to cope with it, and in turn, they must be conscious of that fact that the solution to this disorder may not be found in the short term [27].

\section{Conclusions}

BMS patient management is difficult, and more times than not, a frustrating task. However, it is essential to not only acknowledge the patient but also reassure him/her. The main objective of management is that of providing support to the patient and working towards symptom reduction, rather than total elimination of such symptoms. The complexity of this disease, as well as the ignorance of the mechanisms that cause its onset, are two key topics that need to be further researched. Such insight could enable us to establish effective treatment for this disorder. Finally, it is crucial for us to evaluate the quality of life of those BMS patients, trying to fully comprehend the impact that this condition has on all aspects of their lives.

induced burning mouth syndrome: a new etiological diagnosis. Medicina oral Patología Oral y Cirugía bucal. 2008; 13: E167-E170.

6. Dutrée-Meulenberg RO, Kozel MM, Van Joost T. Burning mouth syndrome: a possible etiologic role for local contact hypersensitivity. Journal of the American Academy of Dermatology. 1992; 26: 935-940.

7. Tourne LP, Fricton JR. Burning mouth syndrome. Critical review and proposed clinical management. Oral Surgery, Oral Medicine, and Oral Pathology. 1992; 74: 158-167.

8. Bergdahl M, Bergdahl J. Burning mouth syndrome: prevalence and associated factors. Journal of Oral Pathology \& Medicine. 1999; 28: 350-354.

9. Thoppay JR, De Rossi SS, Ciarrocca KN. Burning mouth syndrome. Dental Clinics of North America. 2013; 57: 497-512.

10. López-Jornet P, Camacho-Alonso F, Andujar-Mateos P, Sánchez-Siles M, Gómez-Garcia F. Burning mouth syndrome: an 
update. Medicina oral, Patología Oral y Cirugía bucal. 2010; 15: e562-e568.

11. Gao J, Chen L, Zhou J, Peng J. A case-control study on etiological factors involved in patients with burning mouth syndrome. Journal of Oral Pathology \& Medicine. 2009; 38: 24-28.

12. Evans RW, Drage LA. Burning mouth syndrome. Headache. 2005; 45: 1079-1081.

13. Beneyto YM, Jornet PL, Nicolás AV, García VJ. Letter to the Editor: Attitudes among Spanish general dentists in relation to burning mouth syndrome: results of a national survey. Medicina oral, Patología Oral y Cirugía bucal. 2008; 13: e753-e754.

14. Bergdahl M, Bergdahl J. Low unstimulated salivary flow and subjective oral dryness: association with medication, anxiety, depression, and stress. Journal of Dental Research. 2000; 79: 1652-1658.

15. Soares MS, Chimenos-Küstner E, Subirá-Pifarrè C, Rodríguez de Rivera-Campillo ME, López-López J. Association of burning mouth syndrome with xerostomia and medicines. Medicina oral, Patología Oral y Cirugía bucal. 2005; 10: 301-308.

16. Ito M, Kurita K, Ito T, Arao M. Pain threshold and pain recovery after experimental stimulation in patients with burning mouth syndrome. Psychiatry and Clinical Neurosciences. 2002; 56: 161-168.

17. Jääskeläinen SK. Pathophysiology of primary burning mouth syndrome. Clinical Neurophysiology. 2012; 123: 71-77.

18. Sardella A, Carrassi A. BMS: $S$ for syndrome or $S$ for Symptom? A reappraisal of the burning mouth syndrome. Minerva Stomatologica. 2001; 50: 241-246.

19. Lipton JA, Ship JA, Robinson DL. Estimated prevalence and distribution of reported orofacial pain in the United States. Journal of the American Dental Association. 1993; 124: 115-121.

20. Rodrigo MA, Garcia JA. Síndrome de boca ardiente. Gaceta Dental. 2000; 104: 86-88.

21. Silvestre FJ, Bagán JV, Rojo L. Síndrome de boca ardiente: Estudio clínico y biológico. Rev Actual Odonto Estomatolol Esp. 1991; 409: 37-42.

22. Rojo L, Silvestre FJ, Bagán JV, De Vicente T. Prevalence of psychopathology in burning mouth syndrome. Oral Surgery, Oral Medicine, and Oral Pathology. 1994; 78: 312-316.

23. Tarkkila L, Linna M, Tiitinen A, Lindqvist C, Meurman JH. Oral symptoms at menopause-the role of hormone replacement therapy. Oral Surgery, Oral Medicine, Oral Pathology, Oral Radiology, and Endodontics. 2001; 92: 276-280.

24. Grushka M, Sessle B. Taste dysfunction in burning mouth syndrome. Gerodontics. 1988; 4: 254-258.

25. Carlson Cr, Miller CS, Reid KL. Psychosocial profiles of patients with burning mouth syndrome. Journal of Orofacial Pain. 2000; 14: 59-64.

26. Balasubramaniam R, Klasser GD, Delcanho R. Separating oral burning from burning mouth syndrome: unravelling a diagnostic enigma. Australian Dental Journal. 2009; 54: 293-299.

27. Minguez-Sanz MP, Salort-Llorca C, Silvestre-Donat FJ. Etiology of burning mouth syndrome: a review and update. Medicina oral, Patología Oral y Cirugía bucal. 2011; 16: e144-e148.

28. El-Etr M. Critical commentary 3: steroid dysregulation and stomatodynia (burning mouth syndrome). Journal of Orofacial Pain. 2009; 23: 216-218.

29. Cavalcanti DR, Silveira FRX. Alpha lipoic acid in burning mouth syndrome - a randomized double-blind placebo-controlled Trial. Journal of Oral Pathology \& Medicine. 2009; 38: 254-561.

30. Abetz LM, Savage NW. Burning mouth syndrome and psychological disorders. Australian Dental Journal. 2009; 54: 84-93.

31. Mock D, Chugh D. Burning mouth syndrome. International Journal Of Oral Science. 2010; 2: 1-4.

32. de Moraes M, do Amaral Bezerra BA, da Rocha Neto PC, de Oliveira Soares AC, Pinto LP, de Lisboa Lopes Costa A. Randomized trials for the treatment of burning mouth syndrome: an evidence-based review of the literature. Journal of Oral Pathology \& Medicine. 2012; 41: 281-287.
33. Spanemberg JC, Cherubini K, de Figueiredo MA, Yurgel LS, Salum FG. Aetiology and therapeutics of burning mouth syndrome: an update. Gerodontology. 2012; 29: 84-89.

34. Klasser GD, Fischer DJ, Epstein JB. Burning mouth syndrome: recognition, understanding, and management. Oral and Maxillofacial Surgery Clinics of North America. 2008; 20: 255-271.

35. Scala A, Checchi L, Montevecchi M, Marini I, Giamberardino MA. Update on burning mouth syndrome: overview and patient management. Critical Reviews in Oral Biology and Medicine. 2003; 14: $275-291$.

36. Dias Fernandes CS, Salum FG, Bandeira D, Pawlowski J, Luz C. Salivary dehydroepiandrosterone (DHEA) levels in patients with the complaint of burning mouth: a case-control study. Oral Surgery, Oral Medicine, Oral Pathology, Oral Radiology, and Endodontics. 2009; 108: 537-543.

37. Forabosco A, Criscuol M, Coukos G, Uccelli E, Weinstein R, et al. Efficacy of hormone replacement therapy in postmenopausal women with oral discomfort. Oral Surgery, Oral Medicine, and Oral Pathology. 1992; 73: 570-574.

38. Lauria G, Majorana A, Borgna M, Lombardi R, Penza P, et al. Trigeminal small-fiber sensory neuropathy causes burning mouth syndrome. Pain. 2005; 115: 327-332.

39. Silvestre FJ, Serrano C. El syndrome de boca ardiente: revision de conceptos y puesta al día. Medicina oral. 1997; 2: 30-38.

40. Riley JL, Gilbert GH. Orofacial pain symptoms: an interaction between age and sex. Pain. 2001; 90: 245-256.

41. Lamey PJ, Lamb AB, Hughes A, Milligan KA, Forsyth A. Type 3 burning mouth syndrome: psychological and allergic aspects. Journal of Oral Pathology \& Medicine. 1994; 23: 216-219.

42. Helton J, Storrs F. The burning mouth syndrome: lack of a role for contact urticaria and contact dermatitis. Journal of the American Academy of Dermatology. 1994; 31: 201-205.

43. Tammiala-Salonen T, Söderling E. Protein composition, adhesion, and agglutination properties of saliva in burning mouth syndrome. Scandinavian Journal of Dental Research. 1993; 101: 215-218.

44. Gorsky M, Silverman S Jr, Chinn H. Burning mouth syndrome: a review of 98 cases. Journal of Oral Medicine. 1987; 42: 7-9.

45. Main DM, Basker RM. Patients complaining of a burning mouth. Further experience in clinical assessment and management. British Dental Journal. 1983; 154: 206-211.

46. Schmitt RJ, Sheridan PJ, Rogers RS. Pernicious anemia with associated glossodynia. Journal of the American Dental Association. 1988; 117: 838-840.

47. López-Jornet P, Saura-Inglés A, Martínez-Mondéjar B, Bermejo-Fenoll A. Valoración de la tasa de flujo salival en pacientes con diabetes mellitus tipo 1 y tipo 2. Archivos de Odontoestomatol. 1996; 12: 690-697.

48. Eli I, Kleinhauz M, Baht R, Littner M. Antecedents of burning mouth syndrome (glossodynia)--recent life events vs. psychopathologic aspects. Journal of Dental Research. 1994; 73: 567-572.

49. Palacios-Sanchez MF, Jordana-Comín X, García-Sivoli CE. Burning Mouth Syndrome: A retrospective study of 140 cases in a sample of Catalan population. Medicina oral, Patología Oral y Cirugía bucal. 2005; 10: 388-393.

50. Amenábar JM, Pawlowski J, Hilgert J, Hugo FN, Bandeira $\mathrm{D}$, et al. Anxiety and salivary cortisol levels in patients with burning mouth syndrome: case-control study. Oral Surgery, Oral Medicine, Oral Pathology, Oral Radiology, and Endodontics. 2008; 105: 460-465.

51. Grushka M, Epstein JB, Gorsky M. Burning mouth syndrome. American Family Physician. 2002; 65: 615-620.

52. Nasri-Heir C. Burning mouth syndrome. The Alpha Omegan. 2012; 105: 76-81.

53. Lamey PJ, Lewis MAO. Oral medicine in practice: Burning mouth syndrome. British Dental Journal. 1989; 167: 197-200.

54. Lamey PJ, Lamb AB. The usefulness of HAD scale in assesing anxiety and depression in patients with burning mouth 
syndrome. Oral Surgery, Oral Medicine, and Oral Pathology. 1989; 67: 390-392.

55. Lamey PJ. Burning mouth syndrome. Dermatologic Clinics. 1996; 14: 339-354.

56. Charleston L 4th. Burning mouth syndrome: a review of recent literature. Current Pain and Headache Reports. 2013; 17: 336.

57. Chugh D, Mock D. How do I manage a patient with burning mouth syndrome? Journal of Canadian Dental Association. 2013; 79: $\mathrm{d} 41$.

58. Tammiala-Salonen T, Forssell H. Trazodone in burning mouth pain: a placebo-controlled, double-blind study. Journal of Orofacial Pain. 1999; 13: 83-88.

59. Espinosa LS, López JP, Frutos RR. Síndrome de boca ardiente. Eficacia de la aplicación tópica de capsaicina. Estudio Piloto. Avances en Odontoestomatologia. 2004; 20: 297-304.

60. Epstein JB, Marcoe JH. Topical application of capsaicin for treatment of oral neuropathic pain and trigeminal neuralgia. Oral Surgery, Oral Medicine, and Oral Pathology. 1994; 77: 135-140.

61. Bergdahl J, Anneroth G, Perris H. Personality characteristics of patients with resistant burning mouth syndrome. Acta Odontologica Scandinavica. 1995; 53: 7-11.

62. Gremeau-Richard C, Woda A, Navez ML, Attal N, Bouhassira $\mathrm{D}$, et al. Topical clonazepam in stomatodynia: a randomized placebocontrolled study. Pain. 2004; 108: 51-57.

63. Rodríguez de Rivera-Campillo ME, López-López J, Chimenos-Küstner E. Tratamiento del síndrome de boca ardiente con clonacepam tópico. Piel. 2011; 26: 263-268.

64. Rodriguez de Rivera Campillo E, López López J, Chimenos Küstner E. Response to topic Clonazepam in patients with burning mouth syndrome: a clinical study. Bulletin $d u$ Groupèment International Pour la Recherche Scientifique en Stomatologie \& Odontologie. 2010; 49: 19-29.

65. Yamazaki Y, Hata H, Kitamori S, Onodera M, Kitagawa Y. An open-label, noncomparative, dose escalation pilot study of the effect of paroxetine in treatment of burning mouth syndrome. Oral Surgery, Oral Medicine, Oral Pathology, Oral Radiology, and Endodontics. 2009; 107: e6-e11.

66. Ueda N, Kodama Y, Hori H, Umene W, Sugita A, Nakano H, Yoshimura R, Nakamura J. Two cases of burning mouth syndrome treated with olanzapine. Psychiatry and Clinical Neurosciences. 2008; 62: 359-361.

67. Carbone M, Pentenero M, Carrozzo M, Ippolito A, Gandolfo S. Lack of efficacy of alpha-lipoic acid in burning mouth syndrome: a double-blind, randomized, placebo-controlled study. European Journal of Pain. 2008; 13: 492-496.
68. López-Jornet P, Camacho-Alonso F, Leon-Espinosa S. Efficacy of alpha lipoic acid in burning mouth syndrome: a randomized, placebo-treatment study. Journal of Oral Rehabilitation. 2009; 36: 52-55.

69. Spanemberg JC, Cherubini K, de Figueiredo MA, Gomes AP, Campos MM, Salum FG. Effect of an herbal compound for treatment of burning mouth syndrome: randomized, controlled, double-blind clinical trial. Oral Surgery, Oral Medicine, Oral Pathology and Oral Radiology. 2012; 113: 373-377.

70. Oliveira CH, Moraes ME, Moraes MO, Bezerra FA, Abib E, De Nucci G. Clinical Toxicology Study of an Herbal Medicinal Extract of Paullinia cupana, Trichilia catigua, Ptychopetalum olacoides and Zingiber officinale $\left(\right.$ Catuama $\left.^{\circledR}\right)$ in Healthy Volunteers. Phytotherapy Research. 2005; 19: 54-57.

71. Kato IT, Pellegrini VD, Prates RA, Ribeiro MS, Wetter NU, Sugaya NN. Low-level laser therapy in burning mouth syndrome patients: a pilot study. Photomedicine and Laser Surgery. 2010; 28: 835-839.

72. Santos LF, Carvalho AA, Leão JC, Cruz Perez, Castro JF. Effect of low-level laser therapy in the treatment of burning mouth syndrome: a case series. Photomedicine and Laser Surgery. 2011; 29: 793-796.

73. Yang HW, Huang YF. Treatment of burning mouth syndrome with a low-level energy diode laser. Photomedicine and Laser Surgery. 2011; 29: 123-125.

74. Vukoja D, Alajbeg I, Vučićević Boras V, Brailo V, Alajbeg IZ, Andabak Rogulj A. Is effect of low-level laser therapy in patients with burning mouth syndrome result of a placebo? Photomedicine and Laser Surgery. 2011; 29: 647-648.

75. Moore K. Lasers and pain treatment. Laser Part Clinix. 2004; $72: 1-6$.

76. Bjordal JM, Bensadoun RJ, Tunèr J, Frigo L, Gjerde K, Lopes-Martins RA. A systematic review with meta-analysis of the effect of low-level laser therapy (LLLT) in cancer therapy-induced oral mucositis. Supportive Care in Cancer. 2011; 19: 1069-1077.

77. Sun A, Wu KM, Wang YP, Lin HP, Chen HM, Chiang CP. Burning mouth syndrome: a review and update. Journal of Oral Pathology \& Medicine. 2013; 42: 649-655.

78. Crow HC, Gonzalez Y. Burning mouth syndrome. Oral and Maxillofacial Surgery Clinics of North America. 2013; 25: 67-76.

79. Rodríguez-de Rivera-Campillo E, López-López J. Evaluation of the res-ponse to treatment and clinical evolution in patients with burning mouth syndrome. Medicina oral, Patología Oral y Cirugía bucal. 2013; 18: e403-e410. 